\title{
A influência da participação de alunos em práticas esportivas escolares na percepção do clima ambiental da escola
}

\author{
Ana Lúcia dos Santos \\ António C. Simões
}

https://doi.org/10.5628/rpcd.07.01.26

\author{
Escola de Educação Física e Esporte \\ Universidade de São Paulo \\ São Paulo \\ Brasil
}

\begin{abstract}
RESUMO
O estudo visa verificar se a prática esportiva escolar influencia a percepção que os alunos têm do clima ambiental da escola. O clima ambiental é um conjunto de características do ambiente educacional, percebido pelos seus integrantes com certa constância. Todos os elementos da escola influenciam as características deste clima, inclusive o esporte. Os dados foram colectados em escolas públicas estaduais de São Paulo com alunos de treze a quinze anos do ensino fundamental. Através da análise da variável "prática esportiva" comparou-se alunos que têm e que não têm grupos de treinamento em suas escolas. Os resultados obtidos e analisados de acordo com o teste Qui-quadrado ou o teste exato de Fisher indicam com $95 \%$ de confiabilidade que alunos participantes de grupos de treinamento percebem a escola de uma maneira mais positiva do que os alunos que não têm prática esportiva.
\end{abstract}

Palavras-chave: clima ambiental, esporte, educação

\section{ABSTRACT \\ The influence of student's participation in intramural sports in the perception of environment in the school}

The study seeks to verify if the intramural sports influences the student's perception about the school environmental climate. The environmental climate is a group of characteristics of the education atmosphere, noticed by their members with certain constancy. All the elements of school influence the characteristics of this climate, including sports. The data were collected at state public schools of São Paulo, with students between thirteen and fifteen years old of the high school. Through the analyses of the "sportive practice" variable was made a comparison between students who have and who have not intramural sports in their schools. The obtained results and analyzed in agreement with the test Q ui-square or Fisher exact test indicate with $95 \%$ of reliability that students who participate in the training groups perceive the school in a more positive way than students who do not participate in these groups.

Key-words: environmental climate, sport, education 


\section{INTRODUÇÃO}

A prática esportiva escolar está presente em escolas públicas e privadas em todos os níveis de ensino.

Esta actividade, caracterizada por períodos de treinamento extracurriculares e voltada para competições, tem apresentado crescente consistência. Contudo, o esporte neste contexto não deve ser abordado sob o mesmo enfoque das aulas de educação física, nem do esporte competitivo dos clubes e centros especializados. Ainda que não seja uma área onde proliferem estudos no Brasil, é possível encontrar estudos e pesquisas no âmbito internacional que versem sobre o assunto.

Apesar de tais actividades serem distintas do currículo obrigatório, os grupos de treinamento acontecem na escola, portanto estão vinculadas a organização educacional, que em última instância tem como finalidade contribuir para a educação dos indivíduos e a melhoria da sociedade. É necessário investigar as razões que levam a gestão escolar a incluir este tipo de prática no seu cotidiano e reflectir sobre a melhor forma de realizar tais actividades.

O presente estudo pretende colaborar neste sentido, analisando um aspecto em particular, buscando caracterizar a influência da participação dos alunos em práticas esportivas, no que diz respeito à percepção do clima ambiental da escola.

O estudo do clima ambiental é uma tentativa de compreender algumas variáveis do comportamento humano e grupos sociais. O conceito de clima ambiental adoptado neste estudo é o de um conjunto de características próprias de um ambiente que determina a essência das relações dentro das organizações. Este estado é percebido pelos seus membros e produz um efeito no comportamento dos indivíduos (19).

A organização do projecto pedagógico e do cotidiano escolar determina como o aluno percebe o ambiente da organização. Através da análise da variável "prática esportiva" torna-se possível comparar como os alunos de escolas diferentes percebem as modificações do ambiente. É essencial utilizar meios e estratégias para melhorar o clima ambiental da escola quando se busca a participação activa do aluno e uma educação de qualidade.

\section{Educação}

A educação é um desafio e também uma prioridade em nossa sociedade. A justiça social depende da igualdade de oportunidades que são oferecidas aos indivíduos, inclusive a oportunidade de ter acesso ao conhecimento elaborado por esta sociedade integrando-os a dinâmica social. A escola deve ter as características de um espaço democrático que permite aos indivíduos conhecer, compreender os saberes sociais promovendo assim transformações individuais e colectivas, viabilizando-se o exercício pleno da cidadania em todas as suas dimensões. Para sociedade em geral e para o indivíduo, é fundamental que haja um conjunto de iniciativas e medidas que assegurem o direito à escolarização básica e primem pela qualidade educacional em todos os níveis (13). Assegurado o acesso à escola pública, deve haver a preocupação em promover o sucesso do aluno e viabilizar sua permanência na instituição. Consequentemente, a organização escolar precisa estar capacitada para desenvolver acções pedagógicas adequadas, que extrapolem as estruturas formais das aulas, de relacionamentos rígidos entre professores e alunos, e ainda acções fragmentadas.

A qualidade depende essencialmente da compreensão do entorno social, dos conteúdos que se propõe a ensinar, dos meios utilizados para alcançar seus objectivos e da forma de avaliar sua prática. Educar pode ser entendido como o processo que usa métodos adequados para a formação e o desenvolvimento integral de um ser humano. A formação do ser humano deve considerar a observação da cultura, do meio, da apropriação dos conhecimentos, além da elaboração pessoal do conteúdo adquirido.

A escola é insubstituível no processo de inserção da criança no mundo, portanto é fundamental construir um processo pedagógico que seja compatível com este desafio, mesmo que seja extremamente difícil investigar as variáveis que interferem neste processo (2). Sem indicadores confiáveis e um método de avaliação consistente não há como orientar e reorientar as práticas educativas.

\section{Clima ambiental}

Escola e educando deveriam ter uma relação harmoniosa, minimizando conflitos e estabelecendo objectivos comuns. A escola deve ser um espaço que oferece 
condições para que os indivíduos realizem suas tarefas e interajam de maneira produtiva. Somente neste ambiente pode-se formar gente humanizada (9).

Os grupos dentro da escola podem ser formais ou informais e a organização educacional deve explorar o potencial educativo de ambos. É preciso considerar os grupos formais como grupos de comando e grupos de tarefa, e os grupos informais como grupos de interesse comum e grupos de amizade (10).

Assim, a concepção da escola como um todo, leva a ideia de que o sucesso do processo ensino-aprendizagem é algo mais abrangente do que a relação professor-aluno, e que o clima ambiental dentro da escola pode ser decisivo para atingir os objectivos pré-determinados. "Essencialmente, a aprendizagem ocorre através de experiências tidas pelo aluno; ou, por outra, através das suas reacções ao ambiente em que é colocado" (20). Contudo, não é simples manter sob controle um aspecto educativo tão subjectivo, pois é preciso ter consciência que a dinâmica do ambiente é provida de um carácter instável, oscilando entre tranquilidade e turbulência com certa facilidade.

O ambiente escolar é influenciado por um conjunto de factores tais como a arquitectura das instalações físicas, os recursos tecnológicos e pedagógicos de que a escola dispõem, os horários de funcionamento da escola e os indivíduos que directa ou indirectamente interferem no cotidiano escolar.

Os gestores educacionais devem estar conscientes da possibilidade de alterar factores ambientais que interferem nos mecanismos internos de aprendizagem dos indivíduos, desenvolvendo uma postura pró-activa em relação às condições que são ideais para que o projecto pedagógico se desenvolva. As experiências devem ser planejadas e realizadas de forma a potencializar a obtenção do resultado final, produzindo um efeito somatório entre as mesmas (20). O tipo de influência que o meio e os grupos impõem à vida do indivíduo resulta na maneira como este aprende a se comprometer com as organizações e com o tipo de satisfação pessoal que ele almeja. Em se tratando da escola, a diversidade, a complexidade e o propósito das actividades destinadas aos alunos determinam o êxito da acção educativa, seja no processo ensino aprendizagem, seja no desenvolvimento de competências (17).
As relações funcionais e sociais estabelecidas determinam a eficácia do grupo e para tanto o ideal é que este clima ambiental seja prazeroso, coeso, proveitoso, receptivo e positivo, estabelecendo assim uma sensação de conforto e segurança que viabiliza o envolvimento e a capacidade de expressão do indivíduo. O estabelecimento de um clima ambiental favorável condiciona a forma pela qual os alunos respondem às expectativas de aprendizagens significativas. Assim, quanto mais harmónica for a percepção do indivíduo e a realidade que o cerca, melhor é sua interacção com o meio ${ }^{(5)}$. Em contrapartida, quanto mais conflituosa e desajustada esta percepção se apresenta, mais difícil fica o estabelecimento de relações sociais e funcionais.

\section{0 esporte na escola}

O esporte está presente na vida dos indivíduos e particularmente do jovem. A prática esportiva escolar é uma realidade presente em muitas escolas públicas e particulares de São Paulo. Em alguns casos, como em escolas particulares, a prática esportiva é um diferencial utilizado amplamente no marketing das escolas. Em outros casos ela surge pela crença amplamente disseminada que o esporte ajuda a formar e construir o carácter dos indivíduos, além dos benefícios que traz à saúde. Um conceito amplamente divulgado é o de que a participação neste tipo de actividade desempenha uma importante função na melhoria da qualidade de vida dos indivíduos (11). Um dos primeiros lugares que permitem o contacto da criança com o esporte é a escola, pois os grandes centros urbanos não dispõem de espaços colectivos que permitam sua prática de maneira efectiva. A inclusão do esporte na escola acontece naturalmente, por ser um lugar de frequência habitual do aluno e de confiança dos pais. A importância do esporte na escola provém do fato de ser um dos conteúdos da educação física, e também por difundir e promover a cultura, democratizando o acesso de todos os alunos em relação a este tipo de conhecimento (14). Dentro da escola o esporte pode ter diferentes formas de organização e abordagens. As manifestações esportivas no período de vida escolar do adolescente são diversas, indo desde as orientações educativas das práticas escolares esportivas, passando pelas práticas esportivas escolares até a institucionalização 
dos jogos estudantis (18). Faz-se necessário então definir melhor estes termos para que haja uma compreensão apropriada do fenómeno estudado.

"A prática escolar esportiva refere-se ao esporte enquanto um dos conteúdos a ser desenvolvido pela educação física dentro do currículo escolar, enquanto práticas esportivas escolares são actividades extracurriculares que podem ser denominadas turmas de treinamento esportivo, com finalidade de representação escolar em competições ou não" (12, p. 34).

Assim é preciso considerar as diferenças, incluindose nestas particularidades os meios, as finalidades, e a forma de participação dos alunos. Portanto, é fundamental observar-se o fenómeno da prática esportiva escolar com um enfoque diferenciado da educação física, bem como é preciso diferenciá-lo também do enfoque do clube e do esporte profissional.

Independentemente da forma como tais actividades estão estruturadas na escola, elas representam uma dimensão do projecto pedagógico da escola. Aliás, o fato da escola optar ou não por oferecer aos alunos a participação em actividades esportivas, competições e eventos desta natureza, já é um indicador da sua proposta pedagógica.

O esporte é um fenómeno psicossocial e institucional, que é determinado pela conjuntura na qual está inserido e é desenvolvido, e têm a família e a escola como elementos decisivos para o estabelecimento de seus objectivos ${ }^{(18)}$. Neste cenário complexo deve-se considerar a expectativa do próprio aluno, atendendo também suas expectativas. "A iniciação e pratica esportiva escolar deveriam ser elementos auxiliares às manifestações sociais e culturais das crianças em idade escolar, juntamente com a família e a escola" (7).

Devido ao grande número de interacções sociais sua estrutura é dinâmica e por isso a investigação de determinados factores fica comprometida. Outro agravante para delimitar o estudo deste fenómeno é a amplitude da definição de alguns termos.

Actualmente são muitos os autores que insistem em que mais do que apoiar ou opor-se ao esporte infantil e juvenil, deve-se continuar investigando para responder com precisão as perguntas relacionadas a este fenómeno esportivo (8). Deve-se ressaltar que a prática esportiva escolar é a projecção de um património cultural que está além do perímetro da escola e de real significado para os alunos.
É fundamental ressaltar que não cabe nesta abordagem um julgamento de valor sobre a actividade em si, ou quais modalidades, ou género, ou estrutura, ou estratégia na qual o esporte se desenvolve como actividade extracurricular.

Considerando-se este panorama é importante diagnosticar se o jovem percebe o ambiente de forma diferenciada quando tem esta possibilidade de participação esportiva. Como já foi descrito anteriormente o clima ambiental é factor fundamental para que o aluno passe a interagir com o meio de maneira satisfatória.

A princípio, parece que a compreensão da relação entre clima ambiental e práticas esportivas escolares demanda uma análise mais apurada dos conceitos apresentados. Neste sentido este estudo pretende investigar no ambiente das escolas públicas estaduais de ensino fundamental, se a prática esportiva escolar pode influenciar o aluno em sua percepção quanto ao clima ambiental de sua escola.

A escolha das escolas públicas estaduais garante que todas as escolas do estudo estão subordinadas a Secretaria Estadual de Educação, e portanto, obedecem as mesmas orientações pedagógicas, cumprem o mesmo calendário escolar e seguem os mesmos critérios administrativos como mecanismos de contratação, remuneração e promoção de professores e corpo técnico-administrativo. Há uma direcção centralizada pelo Estado, porém a direcção da escola pode escolher se terá ou não actividades extracurriculares. Além disso, foram seleccionadas para o estudo oito escolas que geograficamente estão distribuídas da seguinte forma: duas na região sul, duas na região norte, duas na região leste e duas na região oeste da cidade de São Paulo. Cada par de escolas representa uma escola com prática esportiva escolar e outra sem prática esportiva escolar, localizadas em uma mesma região e com um entorno social similar entre as escolas. Deve-se ressaltar ainda que a colecta de dados foi feita em um curto período de tempo, buscando-se assim limitar a interferência de eventos externos. Enfim, para cumprir o propósito deste estudo é necessário caracterizar a percepção do clima ambiental por parte dos alunos em relação às escolas onde estudam, e que não possuem prática esportiva escolar, bem como caracterizar a percepção do clima ambien- 
tal em escolas que possuem prática esportiva escolar, e ainda a percepção do clima ambiental relacionado ao grupo de treinamento ao qual pertencem dentro das escolas e posteriormente estabelecer uma comparação entre os resultados apresentados pelos grupos.

\section{MATERIAL E MÉTODOS}

\section{Sujeitos}

O estudo contou com a participação de 123 (cento e vinte três) alunos de sétimas e oitavas séries. Todos os alunos deste grupo tinham entre 13 e 15 anos, de ambos os sexos. Para ser considerado apto a fazer parte do estudo foram considerados os alunos que estudavam nas escolas por um período mínimo de seis meses, e nos casos dos grupos de treinamento os alunos frequentavam os treinos por seis meses e haviam participado de uma competição pelo menos. Os alunos que pertenciam aos grupos de treinamento praticavam regularmente as modalidades voleibol, handebol e futebol de salão.

\section{Colecta de dados}

No dia agendado, os alunos entregaram o consentimento dos pais e receberam as fichas de colecta de dados. $\mathrm{O}$ instrumento foi distribuído e lido item por item para que as dúvidas fossem minimizadas. Os alunos dispuseram do tempo necessário e foram encorajados a responder o instrumento de maneira franca e honesta.

\section{Instrumentos}

Inicialmente foi aplicada uma ficha diagnóstica para determinar se o indivíduo correspondia ao perfil adequado para fazer parte da amostra. O instrumento para determinação do 'clima ambiental', faz parte do sistema de avaliação "ACS", pertencente ao Laboratório de Psicossociologia do Esporte - LAPSE e já validado, e foi aplicado com o objectivo de investigar a percepção do indivíduo em relação a determinado grupo. Considerando-se uma escala de 1 a 8 , investigaram-se dez estados a princípio opostos.

\section{Procedimentos de pesquisa}

As instituições escolhidas eram escolas públicas estaduais localizadas nas regiões norte, sul, leste e oeste da cidade de São Paulo. A partir dos critérios já explicados anteriormente, as escolas foram escolhidas de maneira aleatória, variando em tamanho e nível sócio-económico, porém dentro de um mesmo entorno social por região. Assim foi feito contacto com o responsável de cada escola para obtenção da autorização e acordado o procedimento de colecta de dados. Por último explicou-se aos professores e alunos a natureza do estudo, período em que foram preenchidos os formulários de consentimento livre e esclarecido.

A colecta de dados foi feita durante o ano lectivo, no período das aulas e treinamentos esportivos.

\section{Tratamento dos dados}

Os resultados são apresentados através da frequência de resposta para cada fator do instrumento e depois tal frequência foi transformada em percentagem. As variáveis são os dez pares de atributos: agradável/desagradável, aceitável/inaceitável, satisfatório/ insatisfatório, animado/desanimado, produtivo/ improdutivo, alegre/indiferente, coeso/desajustado, caloroso/rebelde, interessante/desinteressante, positivo/negativo. Esses pares de atributos avaliam o clima ambiental.

\section{RESULTADOS}

Os resultados expressos nos Quadros 1, 2 e 3 mostram que é possível verificar a frequência em que os valores aparecem em cada um dos itens que compõe o instrumento. Nos Quadros 1, 2 e 3 os valores em destaque representam as maiores percentagens encontradas por par de atributos.

O Quadro 1 apresenta a percentagem em que cada valor é assinalado pelo grupo de alunos $(n=65)$ que estudam em escolas que não possuem práticas esportivas, caracterizando assim o clima ambiental das escolas estudadas. 
Quadro 1. Resultados em percentagem das respostas por item em escolas que não possuem prática esportiva

\begin{tabular}{lccccccccc}
\hline & 1 & 2 & 3 & 4 & 5 & 6 & 7 & 8 & \\
\hline Desagradável & 6,15 & 0 & 6,15 & 16,92 & 26,15 & 18,46 & 18,46 & 7,69 & Agradável \\
Inaceitável & 1,53 & 1,53 & 12,30 & 15,38 & 23,07 & 18,46 & 20,0 & 7,69 & Aceitável \\
Insatisfatório & 3,07 & 6,15 & 4,61 & 10,76 & 35,38 & 23,07 & 6,15 & 10,76 & Satisfatório \\
Desanimado & 3,07 & 12,30 & 10,76 & 7,69 & 15,38 & 13,84 & 20,0 & 16,92 & Animado \\
Improdutivo & 13,84 & 9,23 & 12,30 & 16,92 & 21,53 & 9,23 & 12,30 & 4,61 & Produtivo \\
Indiferente & 10,76 & 1,53 & 7,69 & 23,07 & 10,76 & 16,92 & 10,76 & 18,46 & Alegre \\
Desajustado & 24,61 & 12,30 & 16,92 & 9,23 & 16,92 & 4,61 & 9,23 & 6,15 & Coeso \\
Rebelde & 15,38 & 15,38 & 15,38 & 15,38 & 18,46 & 9,23 & 9,23 & 1,53 & Caloroso \\
Desinteressante & 3,07 & 9,23 & 9,23 & 13,84 & 26,15 & 24,61 & 9,23 & 4,61 & Interessante \\
Negativo & 7,69 & 4,61 & 6,15 & 18,46 & 27,69 & 13,84 & 9,23 & 12,30 & Positivo \\
\hline
\end{tabular}

O Quadro 2 apresenta a percentagem em que cada valor é assinalado no grupo de alunos que estudam em escolas que possuem práticas esportivas caracterizando assim o clima ambiental das escolas investigadas.

Quadro 2. Resultados em percentagem das respostas por item em escolas que possuem práticas esportivas.

\begin{tabular}{lccccccccl}
\hline & 1 & 2 & 3 & 4 & 5 & 6 & 7 & 8 & \\
\hline Desagradável & 3,44 & 5,17 & 3,44 & 6,89 & 8,62 & 29,31 & 31,03 & 12,06 & Agradável \\
Inaceitável & 5,17 & 1,72 & 5,17 & 3,44 & 6,89 & 24,13 & 41,37 & 12,06 & Aceitável \\
Insatisfatório & 5,17 & 5,17 & 1,72 & 3,44 & 15,51 & 17,24 & 34,48 & 17,24 & Satisfatório \\
Desanimado & 10,34 & 1,72 & 1,72 & 1,72 & 8,62 & 13,79 & 13,79 & 48,27 & Animado \\
Improdutivo & 0 & 5,17 & 5,17 & 8,62 & 12,06 & 15,51 & 27,58 & 25,58 & Produtivo \\
Indiferente & 6,89 & 1,72 & 1,72 & 3,44 & 6,89 & 15,51 & 20,68 & 43,10 & Alegre \\
Desajustado & 12,06 & 6,89 & 3,44 & 3,44 & 18,96 & 17,24 & 18,86 & 18,86 & Coeso \\
Rebelde & 10,34 & 6,89 & 5,17 & 13,79 & 10,34 & 18,96 & 22,41 & 12,06 & Caloroso \\
Desinteressante & 8,62 & 1,72 & 1,72 & 3,44 & 13,79 & 17,24 & 25,86 & 27,58 & Interessante \\
Negativo & 1,72 & 5,17 & 5,17 & 1,72 & 6,89 & 13,79 & 34,48 & 31,03 & Positivo \\
\hline
\end{tabular}

O Quadro 3 apresenta a percentagem em que cada valor é assinalado no grupo de alunos $(n=58)$ que estudam em escolas que possuem práticas esportivas e caracteriza o clima ambiental do grupo de treinamento esportivo nestas escolas.

Quadro 3. Resultados em percentagem das respostas por item em grupos de treinamento

\begin{tabular}{lccccccccl}
\hline & 1 & 2 & 3 & 4 & 5 & 6 & 7 & 8 & \\
\hline Desagradável & 1,72 & 0 & 5,17 & 3,44 & 8,62 & 17,24 & 13,79 & 50,0 & Agradável \\
Inaceitável & 3,44 & 0 & 3,44 & 0 & 13,79 & 12,06 & 20,06 & 46,55 & Aceitável \\
Insatisfatório & 1,72 & 0 & 3,44 & 3,44 & 1,72 & 15,51 & 32,75 & 41,37 & Satisfatório \\
Desanimado & 5,17 & 1,72 & 1,72 & 1,72 & 5,17 & 3,44 & 18,96 & 62,06 & Animado \\
Improdutivo & 3,44 & 0 & 3,44 & 3,44 & 1,72 & 3,44 & 13,79 & 70,68 & Produtivo \\
Indiferente & 1,72 & 1,72 & 5,17 & 3,44 & 8,62 & 3,44 & 10,34 & 65,51 & Alegre \\
Desajustado & 6,89 & 0 & 1,72 & 3,44 & 10,34 & 22,41 & 17,24 & 37,93 & Coeso \\
Rebelde & 1,72 & 10,34 & 5,17 & 6,89 & 10,34 & 15,51 & 20,68 & 29,31 & Caloroso \\
Desinteressante & 1,72 & 3,44 & 0 & 0 & 8,62 & 5,17 & 20,68 & 60,34 & Interessante \\
Negativo & 5,17 & 6,89 & 1,72 & 0 & 1,72 & 3,44 & 13,79 & 67,39 & Positivo \\
\hline
\end{tabular}


Para a análise estatística dos resultados, as respostas foram agrupadas em três categorias, sendo a categoria $\mathrm{A}$ relativa aos valores 1, 2 e 3; a categoria $B$ relativa aos valores 4 e 5; e a categoria $C$ relativa aos valores 7, 8 e 9 . Os dados encontram-se nos quadros a seguir:

\begin{tabular}{|c|c|c|c|c|c|c|c|}
\hline \multirow{2}{*}{ Atributos } & \multicolumn{2}{|c|}{ A } & \multicolumn{2}{|c|}{ Categorias } & \multicolumn{2}{|c|}{ C } & \multirow{2}{*}{ Atributos } \\
\hline & freq & $\%$ & freq & $\%$ & freq & $\%$ & \\
\hline Desagradável & 8 & 12,3 & 28 & 43,1 & 29 & 44,6 & Agradável \\
\hline Inaceitável & 10 & 15,4 & 25 & 38,4 & 30 & 46,2 & Aceitável \\
\hline Insatisfatório & 9 & 13,8 & 30 & 46,1 & 26 & 40,1 & Satisfatório \\
\hline Desanimado & 17 & 26,2 & 15 & 23,1 & 33 & 50,7 & Animado \\
\hline Improdutivo & 23 & 35,3 & 25 & 38,5 & 17 & 26,2 & Produtivo \\
\hline Indiferente & 13 & 20,2 & 22 & 33,8 & 30 & 46,2 & Alegre \\
\hline Desajustado & 35 & 53,8 & 17 & 26,2 & 13 & 20,0 & Coeso \\
\hline Rebelde & 30 & 46,2 & 22 & 33,8 & 13 & 20,0 & Caloroso \\
\hline Desinteressante & 14 & 21,5 & 26 & 40,0 & 25 & 38,5 & Interessante \\
\hline Negativo & 12 & 18,4 & 30 & 46,2 & 23 & 35,4 & Positivo \\
\hline \multicolumn{8}{|c|}{ Quadro 5 - Respostas para cada item em escolas que possuem práticas esportivas } \\
\hline \multirow{2}{*}{ Atributos } & \multicolumn{4}{|c|}{$\begin{array}{c}\text { Categorias } \\
\text { B }\end{array}$} & \multicolumn{2}{|c|}{ C } & \multirow{2}{*}{ Atributos } \\
\hline & freq & $\%$ & freq & $\%$ & freq & $\%$ & \\
\hline Desagradável & 7 & 12,0 & 9 & 15,5 & 42 & 72,5 & Agradável \\
\hline Inaceitável & 7 & 12,0 & 6 & 10,4 & 45 & 77,6 & Aceitável \\
\hline Insatisfatório & 7 & 12,0 & 11 & 19,0 & 40 & 69,0 & Satisfatório \\
\hline Desanimado & 8 & 13,8 & 6 & 10,4 & 44 & 75,8 & Animado \\
\hline Improdutivo & 6 & 10,4 & 12 & 20,7 & 40 & 68,9 & Produtivo \\
\hline Indiferente & 6 & 10,4 & 6 & 10,3 & 46 & 79,3 & Alegre \\
\hline Desajustado & 13 & 22,4 & 13 & 22,4 & 32 & 55,2 & Coeso \\
\hline Rebelde & 13 & 22,4 & 14 & 24,1 & 31 & 53,5 & Caloroso \\
\hline Desinteressante & 7 & 12,0 & 10 & 17,3 & 41 & 70,7 & Interessante \\
\hline Negativo & 7 & 12,0 & 5 & 8,7 & 46 & 79,3 & Positivo \\
\hline \multicolumn{8}{|c|}{ Quadro 6 - Respostas para cada item nos grupos de treinamento } \\
\hline \multirow{2}{*}{ Atributos } & \multicolumn{4}{|c|}{$\begin{array}{c}\text { Categorias } \\
\text { B }\end{array}$} & \multicolumn{2}{|c|}{ C } & \multirow{2}{*}{ Atributos } \\
\hline & freq & $\%$ & freq & $\%$ & freq & $\%$ & \\
\hline Desagradável & 4 & 6,9 & 7 & 12,0 & 47 & 81,1 & Agradável \\
\hline Inaceitável & 4 & 6,9 & 8 & 13,7 & 46 & 79,4 & Aceitável \\
\hline Insatisfatório & 3 & 5,2 & 3 & 5,2 & 52 & 89,6 & Satisfatório \\
\hline Desanimado & 5 & 8,6 & 4 & 6,9 & 49 & 84,5 & Animado \\
\hline Improdutivo & 4 & 6,9 & 3 & 5,2 & 51 & 87,9 & Produtivo \\
\hline Indiferente & 5 & 8,6 & 7 & 12,0 & 46 & 79,4 & Alegre \\
\hline Desajustado & 5 & 8,6 & 8 & 13,8 & 45 & 77,6 & Coeso \\
\hline Rebelde & 10 & 17,2 & 10 & 17,2 & 38 & 65,6 & Caloroso \\
\hline Desinteressante & 3 & 5,2 & 5 & 8,6 & 50 & 86,2 & Interessante \\
\hline Negativo & 8 & 13,7 & 1 & 1,8 & 49 & 84,5 & Positivo \\
\hline
\end{tabular}


Com o objectivo de verificar se existem diferenças estatísticas entre a percepção do clima ambiental de escolas que não possuem práticas esportivas com as que possuem, foi comparada a frequência das categorias de cada par de atributos referente às escolas sem prática com seu par coincidente nas escolas com prática esportiva. A mesma metodologia foi empregada para verificar a existência ou não de diferenças entre o clima ambiental de escolas que possuem práticas esportivas e os grupos de treinamento.

Para análise estatística, utilizou-se o teste de Qui- quadrado (4). No Quadro 8 houve um caso em que a frequência esperada nas caselas foi inferior a 5, o que invalida esse teste. Assim, para superar o problema da análise feita na Quadro 8, utilizou-se o teste exato de Fisher (1).

Vale ressaltar que para a análise do Quadro 7, podem-se utilizar tanto as estatísticas do teste Quiquadrado quanto à do teste exato de Fisher. No entanto, para o Quadro 8, pode-se utilizar somente o teste exato de Fisher, pois para o item atributos positivo/ negativo o teste Qui-quadrado não é válido.

Quadro 7. Estatísticas obtidas nas análises, comparando escolas sem prática esportiva com as escolas onde são desenvolvidas essas práticas.

\begin{tabular}{lcccc}
\hline Itens de atributos & \multicolumn{2}{c}{ Qui-Quadrado $(\mathrm{g} . \mathrm{l}=2 ; \mathrm{n}=123)$} & \multicolumn{2}{c}{ Teste exacto de Fischer } \\
& Valor & $\mathrm{p}$-valor & Valor & 0,0001 \\
\hline 1. Agradável/Desagradável & 11,84 & 0,0027 & 0,0024 \\
2. Aceitável/Inaceitável & 14,82 & 0,0006 & 0,0000 & 0,0005 \\
3. Satisfatório/Insatisfatório & 11,66 & 0,0029 & 0,0001 & 0,0026 \\
4. Animado/Desanimado & 8,30 & 0,0158 & 0,0006 & 0,0181 \\
5. Produtivo/Improdutivo & 23,49 & $<, 0001$ & 0,0000 & 0,0000 \\
6. Alegre/Indiferente & 14,74 & 0,0006 & 0,0000 & 0,0005 \\
7. Coeso/Desajustado & 18,30 & 0,0001 & 0,0000 & 0,0001 \\
8. Caloroso/Rebelde & 15,51 & 0,0004 & 0,0000 & 0,0004 \\
9. Interessante/Desinteressante & 12,97 & 0,0015 & 0,0000 & 0,0015 \\
10. Positivo/Negativo & 26,53 & $<, 0001$ & 0,0000 & 0,0000
\end{tabular}

Quadro 8 - Estatísticas obtidas nas análises, comparando os grupos de treinamento com as escolas onde são desenvolvidas práticas esportivas.

\begin{tabular}{lcccc}
\hline Itens de atributos & \multicolumn{2}{c}{$\begin{array}{c}\text { Qui-Quadrado ( } \mathrm{g} . \mathrm{l}=2 ; \\
\text { Valor }\end{array}$} & $\begin{array}{c}\text { n=123) } \\
\text { p-valor }\end{array}$ & \multicolumn{2}{c}{ Teste exacto de Fischer } \\
Valor & 0,0279 & 0,5323 \\
\hline 1. Agradável/Desagradável & 1,35 & 0,5094 & 0,0331 & 0,6397 \\
2. Aceitável/Inaceitável & 1,11 & 0,5727 & 0,0013 & 0,0235 \\
3. Satisfatório/Insatisfatório & 7,74 & 0,02 & 0,0315 & 0,5449 \\
4. Animado/Desanimado & 1,36 & 0,5063 & 0,0017 & 0,0319 \\
5. Produtivo/Improdutivo & 7,13 & 0,0283 & 0,0530 & 1,0000 \\
6. Alegre/Indiferente & 0,17 & 0,9195 & 0,0013 & 0,0370 \\
7. Coeso/Desajustado & 6,94 & 0,0311 & 0,0145 & 0,4378 \\
8. Caloroso/Rebelde & 1,77 & 0,4131 & 0,0078 & 0,1429 \\
9. Interessante/Desinteressante & 4,16 & 0,1251 & 0,0194 & 0,3175 \\
10. Positivo/Negativo & $*$ & $*$ & & \\
\hline
\end{tabular}

* casos com valores esperados menores que 5. 


\section{DISCUSSÃO}

Os Quadros 1, 2 e 3 representam os resultados obtidos de acordo com o instrumento de pesquisa original. Nos Quadros 4, 5 e 6 há o agrupamento de resultados em categorias. O Quadro 4 mostra que as percentagens relacionadas aos atributos na categoria C variam entre $20 \%$ e $50,7 \%$ das respostas. A análise dos resultados apresentados no Quadro 5 demonstra que na categoria $\mathrm{C}$ as percentagens variam entre $53,5 \%$ e $79,3 \%$ o que revela que a percepção que o aluno tem da escola que promove a prática esportiva escolar é em sua maioria positiva. No Quadro 6 observa-se que as percentagens na categoria $C$ variam entre $65,6 \%$ a $89,6 \%$, o que enfatiza a percepção favorável que estes alunos têm em relação aos grupos de treinamento. Estes resultados parecem reforçar a ideia de que o esporte na escola tem um significado importante para o jovem (15). Analisando os Quadros 7, 8 e os p-valores do teste Qui-quadrado ou o teste exato de Fisher, é possível ter $95 \%$ de confiança que, comparando as escolas onde não existe a prática esportiva escolar com as que possuem tal prática, nota-se que existe diferença para todos os itens de atributos.

Os dados indicam que o envolvimento em programas esportivos podem contribuir positivamente para o desenvolvimento social dos participantes (15), o que seria amplamente favorável a percepção de um clima ambiental salutar.

Em vista dos objectivos estabelecidos no presente estudo, pode-se concluir que existe uma diferença significativa na percepção que os alunos têm do clima ambiental das escolas ao compararem-se escolas que possuem e escolas que não possuem práticas esportivas escolares.

Constata-se também que as escolas que possuem práticas esportivas escolares são percebidas de uma maneira melhor pelos alunos, do que escolas que não possuem tais práticas. Apesar de não ser encontrada uma diferença significativa na percepção do clima ambiental como um todo; ao se comparar escolas que possuem práticas esportivas e os grupos de treinamento; é possível identificar uma tendência dos alunos perceberem o clima ambiental dos grupos de treinamento de maneira mais adequada do que o clima da própria escola.
Os resultados obtidos assemelham-se a um estudo que analisa a percepção do ambiente em aulas de educação física escolar (6), no qual há a conclusão de que os alunos apresentaram uma representação positiva sobre o ambiente de aprendizagem das aulas de educação física, mesmo que neste estudo a atividade investigada seja a aula curricular.

Contudo, assim como outros estudos já indicaram

(3), para fornecer uma argumentação mais consistente, novos estudos devem ser realizados, os quais devem examinar os ganhos ou perdas, no que tange aos aspectos sociais dos indivíduos que participam de actividades extracurriculares em comparação com indivíduos que não participam. Deve-se considerar que os efeitos de programas esportivos sobre o comportamento dos indivíduos variam profundamente em função do contexto social e das condições em que as experiências esportivas acontecem (16).

\section{AGRADECIMENTO}

Agradecemos aos alunos, professores e directores das escolas públicas do estado de São Paulo que tornaram possível a colecta de dados desta pesquisa. Este estudo foi realizado no âmbito do trabalho de mestrado na Escola de Educação Física e Esporte da Universidade de São Paulo.

\section{CORRESPONDÊNCIA \\ Ana Lúcia P. Dos Santos}

R. Elisa Rodrigues, 49 - Planalto Paulista

São Paulo - SP - Brasil CEP 04058050

ana.padrao@ superig.com.br

analuciapadrao@ig.com.br 


\section{REFERÊNCIAS BIBLIOGRÁFICAS}

1. Agresti A (1990). Categorial data analysis. New York: Wiley

2. Aratangy L (2001). Qual a melhor escola para seu filho? Veja São Paulo 39: 31

3. Artinger L (2006). The social benefits of intramural sports. Naspa Journal 43: 69-86

4. Bussab W, Morettin PA (2002). Estatística básica. São Paulo: Saraiva

5. Centro de estudos e pesquisas em educação, cultura e ação comunitária (2000). ONG e esportes: a cidadania entrando em campo. São Paulo: Cenpec.

6. Condessa I (2004). A percepção dos alunos sobre o ambiente de aprendizagem nas aulas de Educação Física. Um estudo nos Açores. Revista Portuguesa de Ciências do D esporto 4: 172-173.

7. Conselho federal de educação física (2002). Intervenção do profissional de Educação Física. Rio de Janeiro: Confef

8. Ferrando MG (1990). A spectos sociales del deporte: una reflexión sociológica. Madrid: Alianza.

9. Garcia OG (2000). Revitalizando a prática escolar cotidiana através dos relatos e troca de experiência. Revista de Educação A EC 29: 103-111.

10. Gibson JL, Ivancevich JM, Donnelly JM (1988). Organizações. São Paulo: Atlas.

11. Iso-Ahola, S. The social psychology of leisure and recreational . In: Artinger L. (2006). The social benefits of intramural sports. Naspa Journal 43:69-86.
12. Lucato $S$ (2000). Iniciação e prática esportiva e suas dimensões sócio-culturais na percepção dos pais. Dissertação de Mestrado. São Paulo: Escola de Educação Física e Esporte da Universidade de São Paulo.

13. Menezes LC (2001).Os papéis dos ensinos médio e superior. Veja São Paulo 34: 82.

14. Paes RR (2002) A pedagogia do esporte e os jogos coletivos. In: De Rose D (Org.). Esporte e atividade física na infância e na adolescência: U ma abordagem multidisciplinar. Porto Alegre: Artmed, 89-98.

15. Rees C R (2001) Character development, moral development, and social responsibility in physical education and sport: towards a ythesis of subdisciplinary perspectives. International Journal of Physical Education 38:52-59.

16. Sage G. (1998) Does sport affect character development in athletes? Journal of Physical Education, Recreation and Dance 69:15-18.

17. Salvador CC (2000). Psicologia do ensino. Porto Alegre: Artmed.

18. Simões AC, Bohme MTS, Lucato S (1999) A participação dos pais na vida esportiva dos filhos. Revista Paulista de Educação Física 13: 34-35.

19. Tagiuri R (1969). Person perception and interpersonal behavior. Stantdford: Standford University Press.

20. Tyler RW (1976). Princípios básicos do currículo e ensino. Rio de Janeiro: Globo. 